\title{
Biotic interactions experienced by a new invader: effects of its close relatives at the community scale
}

Post-print/Accepted manuscript

Steven B. Hill

Peter M. Kotanen

Hill SB, Kotanen PM. 2012. Biotic interactions experienced by a new invader: effects of its close relatives at the community scale. Botany 90(1): 35-42 doi:10.1139/b11-084

\section{HOW TO CITE TSPACE ITEMS}

Always cite the published version, so the author(s) will receive recognition through services that track citation counts, e.g. Scopus. If you need to cite the page number of the TSpace version (original manuscript or accepted manuscript) because you cannot access the published version, then cite the TSpace version in addition to the published version using the permanent URI (handle) found on the record page. 
Biotic interactions experienced by a new invader: effects of its close relatives at the community scale

Steven B. Hill ${ }^{1}$ and Peter M. Kotanen ${ }^{2 *}$

Department of Ecology and Evolutionary Biology

University of Toronto Mississauga

3359 Mississauga Road N

Mississauga ON

L5L 1C6

Canada

1e-mail: burtonhill@gmail.com

2e-mail: peter.kotanen@utoronto.ca

* Author for correspondence

tel: 905-828-5365; fax: 905-828-3792

Total length: 5555 words; 25 pp

Tables: 2

Figures: 3 
Abstract The success of non-indigenous species may be influenced by biotic interactions during the initial stages of invasion. Here, we investigated whether a potential invader, Solidago virgaurea, would experience more damage by natural enemies in communities dominated by close relatives. than those without; interactions with mutualistic mycorrhizae might partially counteract these effects. We monitored damage experienced by $S$. virgaurea planted into communities with native congeners and without close relatives. Community type was crossed with a vegetation removal treatment to assess the combined effects of herbivory and competition on survival. We also evaluated growth of $S$. virgaurea in a greenhouse experiment where seedlings were exposed to soil biota sampled from these communities, with sterile controls. Overall, community type did not affect levels of herbivory or plant survival. Removal of surrounding vegetation resulted in reduced damage and increased survival; these effects were largest in grass-dominated communities. Soil sterilization reduced root growth and tended to reduce shoot growth, especially when compared with plants inoculated with biota collected near congeners. Overall, our results suggest that the presence of close relatives is unlikely to make old-field communities more resistant to invasion by S. virgaurea; instead, soil biota might facilitate growth in communities dominated by close relatives.

Keywords disturbance; herbivory; invasion; pathogens; soil biota; Solidago virgaurea 


\section{Introduction}

Almost all ecosystems on Earth have been affected by non-indigenous (exotic) species (Mack et al. 2000; Pimentel et al. 2000; Crall et al. 2006). Despite their ubiquity, predicting which exotic species will succeed and become invasive remains difficult. In part, this may be a consequence of the lack of data from the early stages of the invasion process, when the first non-native populations are becoming established (Mack et al. 2000). This probably is the moment at which many invasions fail, yet such failures are likely to go unnoticed, as new populations still are small and inconspicuous (Elton 1958; Williamson 1996). The factors determining this initial success or failure may not be the same as those that influence an invader's subsequent spread (Williamson 1996).

One factor affecting the success of founder populations may be biotic interactions with the preexisting flora and fauna (Levine et al. 2004; Mitchell et al. 2006). For instance, the "Enemy Release Hypothesis" (ERH) suggests one reason that exotic plants succeed is that they leave behind herbivores and pathogens in their native range (Keane and Crawley 2002; Mitchell and Power 2003; Torchin et al. 2003). However, this often may be a transient effect: exotic plants can rapidly acquire enemies in their new range, leading to significant levels of damage (Hawkes 2007, Brandl et al. 2008). The rate at which a newly founded population acquires such enemies may depend on the composition of the surrounding plant community (e.g., MacKay and Kotanen 2008). Since herbivores (Odegaard et al. 2005; Brandle and Brandl 2006; Weiblen et al. 2006) and pathogens (Brandle and Brandl 2006; Gilbert and Webb 2007) are often shared among close relatives, it might be expected that an invader would be more likely to rapidly accumulate enemies in a community containing closely related native species. Evidence to support this 
pattern is mixed: for instance, Cappuccino and Carpenter (2005) and Hill and Kotanen (2010, 2011) found no relationship between taxonomic isolation and herbivore damage to plants in eastern North America, whereas Dawson et al. (2009) and another of our studies (Hill and Kotanen 2009) both found evidence that phylogenetically isolated exotics experience lower rates of herbivory.

Other biotic interactions amongst relatives also may influence the initial establishment of invaders (Mack 1996; Webb et al. 2002, Mitchell et al. 2006). For instance, not all biotic interactions are necessarily negative: mutualistic associations such as mycorrhizae may be critical for invasion success (Richardson et al. 2000). Recent evidence suggests even arbuscular mycorrhizal fungi often may have host-specific effects (Klironomos 2002, 2003); if so, then availability of a suitable mycorrhizal fungus might be more likely when an invader has close relatives in the local native flora (Richardson et al. 2000). Therefore, net effects of soil biota may include both negative effects of soil pathogens and positive effects of compatible mycorrhizae (MacKay and Kotanen 2008).

Here, we investigated whether experimentally established founding populations of a potential invader, Solidago virgaurea L., would experience stronger biotic interactions in communities with native Solidago spp. vs. communities dominated by phylogenetically and phenotypically distinct grasses. Specifically, we tested two hypotheses:

1) S. virgaurea should experience greater foliar herbivore damage when grown in the presence of native Solidago spp. than when grown with unrelated plants. 
2) Effects of soil biota on S. virgaurea should be stronger when native Solidago spp. are present in the surrounding community.

We experimentally evaluated Hypothesis 1 by comparing foliar damage and survival for $S$. virgaurea planted in communities dominated by native Solidago spp. vs. grass. We also included a competitor removal treatment in this experiment, to see if any effects of herbivory were likely to be dependent on the presence of competitors. In this experiment, we examined the net effect of the entire folivore community; net damage, rather than damage by any specific herbivore, is likely to determine plant performance (Keane and Crawley 2002). Hypothesis 2 was tested in a greenhouse experiment in which we compared growth of plants in sterilized soil vs. soil inoculated with biota (including both pathogens and mutualists) from Solidago and grassdominated sites. In this experiment, we would expect a net positive effect of soil sterilization if pathogens are relatively more important than mycorrhizae; a net negative effect of sterilization would indicate if mycorrhizae dominate plant performance.

\section{Materials and Methods}

\section{Study area}

This study was conducted at the University of Toronto's Koffler Scientific Reserve at Jokers Hill (KSR), Regional Municipality of York, in southern Ontario, Canada $\left(44^{\circ} 02^{\prime} \mathrm{N}, 79^{\circ} 31^{\prime} \mathrm{W}, 300 \mathrm{~m}\right.$ ASL). This 350-ha site lies within the Oak Ridges Moraine, and is dominated by prominent hills with a thin organic layer over deep glacial sands. Vegetation is a mixture of old-fields supporting a diverse range of native and exotic plants, hardwood (maple-beech-hemlock) forest, and conifer plantations. Further information may be found at http://www.ksr.utoronto.ca. 
Study species

Solidago (goldenrod) is a primarily North American genus of Asteraceae. The only exception is Solidago virgaurea L., which is a perennial native to Europe and Asia (Jobin et al. 1996). In its native range $S$. virgaurea grows in many habitats including rocky outcrops, disturbed areas, and old-fields (Davis et al. 2000). The species is not yet naturalized in North America, but can readily be found at horticultural stores; for our experiments, $S$. virgaurea seeds were purchased from a local seed supply store in southern Ontario.

North American Solidago species such as S. gigantea Ait. and S. altissima L. are successful invaders throughout much of Europe (Jakobs et al. 2004), where they can co-occur regionally with the native $S$. virgaurea (Jobin et al. 1996). Therefore, we anticipated that $S$. virgaurea would have the ecological amplitude to grow with North American Solidago species at this study site. The two representative native species that we considered were Solidago cf. canadensis L. (including Solidago canadensis and Solidago altissima, hereafter S. canadensis) and Solidago nemoralis Ait.

\section{Field experiment (Hypothesis 1)}

In the spring of 2006, we established 15 study locations representing three community types: five in meadows dominated by grasses (primarily Bromus inermis and Poa pratensis), five in meadows dominated by Solidago canadensis, and five in meadows containing a mixture of Solidago canadensis and Solidago nemoralis. Meadows were an average \pm SE of $221 \mathrm{~m} \pm 30 \mathrm{~m}$ apart (based on nearest neighbour distances), and in most cases separated by natural or 
anthropogenic features such as forest communities, hedgerows, or roads. Communities with only S. canadensis had the highest mean density of native Solidago (33.92 stems $\mathrm{m}^{-2}$ ), whereas grassdominated communities had the lowest (1.04 stems $\mathrm{m}^{-2}$ ), and mixed Solidago communities were intermediate $\left(8.17\right.$ stems $\mathrm{m}^{-2}$ ). In general, edaphic conditions were similar across these community types; however, grass and S. canadensis usually dominated on more mesic sites, whereas S. nemoralis tended to co-occur with these species on drier soils.

At each study location, we planted 20 lab-germinated S. virgaurea seedlings into the respective meadows, where the competing vegetation was randomly chosen either to be left intact or to be removed ( $\mathrm{n}=10$ in each case). Experimental plants were spaced at least two metres apart. Vegetation removal included digging up all the plant biomass in an approximately $1 \mathrm{~m}$ diameter circle around the focal plant; we replaced as much of the organic soil horizon as possible. Plots were weeded on a weekly basis throughout the growing season. Any surviving S. virgaurea were carefully removed at the end of the experiment to preclude the risk of escape.

During June, July, and August 2006 and June 2007, we determined whether each S. virgaurea had survived, and if so, the amount of leaf damage it had experienced. At each sampling, damage to surviving plants was measured in two ways: the proportion of leaves with damage, and for damaged leaves, the proportion of area affected to the nearest $5 \%$. These measures were then multiplied to produce an estimate of the total fraction of leaf area damaged per plant:

proportion of leaf area damaged per plant $=$ fraction of leaves damaged per plant $\times$ mean proportion of area damaged per affected leaf 
The estimate ranges between 0 and 1 , where 0 indicates that leaves had no damage, and 1 indicates that all leaf area had been consumed. For the statistical analyses (see below) we calculated the mean of this value over the four sampling episodes as an index of overall herbivore pressure. This index provides an integrated measure of damage from all sources experienced by a plant throughout this experiment, and thus the overall impact of herbivores. A variety of herbivores likely contributed to the damage we observed. Leaves clipped at the base of the petiole were believed often to have been browsed by vertebrates; this type of damage typically was combined with fecal pellets from voles, mice, or rabbits. Leaves that had been clipped but remained below the plant may have been removed by slugs or snails. Missing leaf tissue either at or within the leaf margin was believed to have been removed primarily by insects.

\section{Greenhouse experiment (Hypothesis 2)}

In January 2008, soil was collected from each of the 15 sites used in our field experiment and brought back to the University of Toronto at Mississauga, where it was kept in refrigerators at $4^{\circ} \mathrm{C}$ for 2 days. These soil samples were then either sterilized by autoclaving (two consecutive 20 min cycles: c.f. MacKay and Kotanen 2008), or were left non-sterile. Pots (70mm diameter) were then filled with approximately 100g of a common growth medium (sand mixed with potting soil and sterilized) mixed with 5 g of either sterilized or non-sterilized field soil; each pot received soil from only a single field site. Using only a small amount of sterile or non-sterile inoculum per pot minimizes the risk that results will be biased by physical or chemical differences produced by sterilization. We replicated each site and treatment combination five times for a total of 150 pots. A single lab-germinated seedling of $S$. virgaurea was planted in each pot on 11 January 
2008. Pots were maintained in a greenhouse until harvest on 24 March 2008, when plants were collected, separated into root and shoot, dried, and weighed; a longer experiment would increasingly risk producing misleading results, as pots are expected gradually to be colonized by greenhouse-inhabiting organisms. Comparing plant growth between sterile and nonsterile treatments estimates the combined initial effect of both soil pathogens and mutualists on a seedling, rather than soil feedback over successive generations (e.g., Klironomos 2002).

\section{Statistical analyses}

For the field experiment, we used split-plot factorial analysis of variance (Kirk 1995) to compare damage and survival among community and vegetation removal treatments; the model included terms for community type $(n=3)$, meadow nested in community type $(n=5)$, vegetation removal $(n=2)$, and the community type $\times$ vegetation removal interaction. Community type, vegetation removal, and their interaction were fixed effects; meadow nested within community was a random effect. We analyzed mean damage for each meadow $\times$ treatment combination rather than results for each individual plant to avoid pseudoreplication and maintain a balanced experimental design; results are very similar when the data were not pooled in this manner. For statistical analyses, proportional damage and survival measurements were Z-transformed to linearize the data and better meet statistical assumptions (Crawley 2007).

For the greenhouse experiment, we again used a split-plot factorial analysis of variance to compare the effects of soil biota from different community types on the biomass of plant shoots and roots; community type, sterilization treatment, and their interaction were considered fixed effects, and meadow nested in community type was considered a random factor. Again, we used 
the means of meadow $\times$ treatment replicates $(n=30)$ in our analysis to create a balanced design and to provide more precise estimates of biomass; results are very similar when the data were not pooled in this manner. We also used the same model to evaluate whether Z-transformed survival of $S$. virgaurea seedlings was influenced by treatment type.

All statistical analyses were done using traditional mixed effect analysis of variance in JMP v.5 (SAS Institute Inc. 2002). Means are reported \pm 1 standard error. For clarity, results in our figures are presented in original units based on back-transformed parameter estimates.

\section{Results}

Field experiment (Hypothesis 1)

On average, S. virgaurea experienced similar levels of foliar damage in all community types

(Table 1; Fig. 1). Browsing, presumably by vertebrates, was the most frequent form of leaf damage (16.82 $\pm 3.76 \%$ of leaf area per plant); invertebrates (snails and insects) were suspected of damaging $14.33 \pm 0.95 \%$ of leaf area. Damage was significantly reduced when vegetation was removed (Table 1; Fig. 1), but this effect was not consistent across communities, as indicated by a significant interaction term; instead, damage was greatest in intact grass communities but also declined the most when these communities were disturbed by the removal of adjacent vegetation.

The proportion of plants that survived from June 2006 to June 2007 did not differ among community types (Table 1; Fig. 2). Removal of adjacent vegetation however, resulted in significantly higher survival (Table 1). The effect of vegetation removal nearly differed significantly among community types $(\mathrm{p}=0.056)$, suggesting a potential community type $\times$ 
vegetation removal interaction. Increases in survival were greatest in grass-dominated communities, intermediate in S. canadensis sites and lowest in mixed Solidago sites (Fig. 2), though only in grassy sites was this increase significant $(\mathrm{p}<0.05$ : Tukey HSD).

\section{Greenhouse experiment (Hypothesis 2)}

Of the 150 plants grown for this experiment, 62 survived the 8-week growth period. Community type $\left(F_{2,12}=0.257\right)$, treatment $\left(F_{1,12}=1.500\right)$, and their interaction $\left(F_{2,12}=0.132\right)$ were not statistically related to seedling mortality $(p>0.05)$. At least one representative for each site $\times$ treatment combination survived, allowing the experiment to be analyzed with a balanced design. Nonetheless, given the modest level of replication represented by the survivors, we have indicated below results with p between 0.05 and 0.10 .

Effects of treatments on plant biomass were only realized through analyzing shoot and root data separately. Shoot biomass tended to be lower for plants inoculated with soil from grass communities, followed by Solidago canadensis communities and mixed Solidago communities (Fig. 3a), though this trend was marginally nonsignificant $(\mathrm{p}=0.061$ : Table 2$)$. Plants grown in sterilized soil also tended to be smaller than those in non-sterilized soil, though this result again was marginal $(p=0.089)$. The interaction between community type and soil sterilization was non-significant (Table 2), even though growth tended to be improved more by soil biota from Solidago communities than from grass communities (Fig. 3a). When the difference in shoot growth between non-sterile vs. sterile soil for pooled Solidago communities was compared to that for grassy sites using a t-test, these community types still did not differ significantly $\left(\mathrm{t}_{13}=\right.$ 1.317, $\mathrm{p}=0.211$. 
Inoculation tended to have similar, but more pronounced, effects on root biomass (Table 2). Root mass was greater for plants inoculated with soils from Solidago communities than for plants inoculated with soil from grassy sites (Fig. 3b), though this result was marginally nonsignificant $(p=0.056)$. As well, plants grown in non-sterilized soils produced significantly (Table 2 ) more root biomass than plants in sterile soils (Fig. 3b). There was no significant interaction between community and soil sterilization (Table 2), though again there was a trend for a larger positive effect of soil biota from Solidago soils. When the difference in shoot growth between non-sterile vs. sterile soil for pooled Solidago communities was compared to that for grassy sites using a ttest, there was a marginally nonsignificant trend $\left(\mathrm{t}_{13}=1.845, \mathrm{p}=0.088\right)$ : increases in root growth tended to be higher in soils derived from Solidago communities.

\section{Discussion}

As in much of eastern North America, the dominant species in our old fields were either Asteraceae (primarily Solidago spp.; also Aster spp.) or grasses. By choosing to compare performance of Solidago virgaurea in these two backgrounds, we are considering the habitats it is most likely to encounter: one dominated by congenerics, one by unrelated species. This approach does not provide a general test of whether the presence of congenerics is more important than presence of other phenotypically similar species, but does allow us to compare the results when $S$. virgaurea finds itself in the presence of common relatives vs. non-relatives.

In part, the success of a newly-arrived invader likely depends on both direct and indirect biotic interactions with native species in its new range (Mack 1996; Rejmánek 1996; Mitchell et al. 
2006). For S. virgaurea, we found that plants where adjacent vegetation was left intact experienced more foliar damage and lower survival than plants where the immediately surrounding vegetation had been removed; however, there were no indications that plants suffered more damage when native Solidago spp. were present in higher abundance in the adjacent meadow community. Soil biota had a positive net effect on growth of roots and (marginally) of shoots; there were weak indications this benefit may be stronger for biota sampled from near native congeners. Given the spatial proximity of our sites and the general abundance of Solidago spp. throughout this area, it is unlikely that any site was truly isolated from sources of Solidago-specific herbivores and pathogens; thus, our results reflect the importance of the local plant community, rather than the presence or absence of native Solidago in the regional flora.

\section{Hypothesis 1: effects of relatives on foliar damage}

The folivory that we observed reflects the net effect of the entire herbivore community, including generalists, specialists, vertebrates, and invertebrates; we argue that this net damage, rather than damage by any specific folivore, is likely to be the most important predictor of plant success. This said, while invertebrates likely were responsible for a significant fraction of folivory, the most common single source of leaf damage was suspected to be mammalian browsing. Meadow voles (Microtus pennsylvanicus) are common at KSR, and likely were the principal vertebrate herbivores; previous studies have shown that these generalists can have large impacts on the composition of vegetation in grassland and forest edge habitats, especially during peak abundance years (Manson et al. 2001; Kauffman and Maron 2006). Reduced damage to plants in disturbed treatments likely resulted from voles avoiding these open sites: other research has 
found foraging by M. pennsylvanicus can be influenced more by the presence of intact vegetation cover than by vegetation composition (Belanger and Bergeron 1987; Moenting and Morris 2006).

The impacts of herbivores likely were compounded by competition from resident vegetation, reducing plants' ability to tolerate herbivory (Strauss and Agrawal 1999) and increasing mortality in undisturbed sites. Cover was especially high (nearly 100\%) in intact grass and S. canadensis communities, where experimental plants often were overtopped by the surrounding vegetation. In two S. canadensis sites and one grass site no plants survived (out of 10 initially planted) when resident vegetation was left intact, vs. 4 - 6 plants surviving when resident vegetation was removed in the same sites. Numerous other experiments have shown that removing resident vegetation significantly improves establishment and vigour of individual invaders, though, as with our study, the specific role of competition often is less clear (Levine et al. 2004).

There was little evidence that plants close to native Solidago spp. were at greater risk of herbivore damage. This is consistent with the effects expected of generalist herbivores such as meadow voles, which should be relatively insensitive to the presence of closely related plants. Instead, plants in intact grassy sites tended to suffer the most herbivory, likely because of the dense cover in those locations. Similarly, many (but not all) of the insects and snails attacking our plants probably were generalists unlikely to be influenced by the presence of congeneric hosts. This likely is the situation for many newly-arrived invaders; such species may lose their specialist enemies, but still have to contend with a diverse array of generalists in invaded sites 
(Liu \&and Stiling 1996). It does not matter if damage by specialists is reduced, if damage by generalists more than compensates (Parker and Hay 2005).

Nonetheless, we did find some exceptions. Of the invertebrate herbivores observed on $S$. virgaurea, Microrhopala vittata (Fabricius) (Chrysomelidae) and Trirhabda canadensis Kirby (Chrysomelidae) are known to specialize on native Solidago spp. (Maddox and Root 1987; Carson and Root 1999; Stireman et al. 2005), and were found on experimental plants in all three community types. Experimental work has shown that both of these beetles can reduce the abundance of their hosts, particularly in outbreak years (Carson and Root 1999), but a major outbreak of these herbivores did not occur during our field experiment; a different result might have occurred had this been the case. It might be expected that such specialists should be more abundant close to their host plants (Janzen 1970; Connell 1971); however, the fact that we did not detect evidence of increased herbivory in congeneric-dominated communities suggests that this effect, if it occurred, was obscured by damage from rodents and generalist invertebrates. Janzen-Connell type effects also would only be detected if the specialists of the native species found the invading relative a suitable host; an assumption that was supported anecdotally in our study through observations of these two herbivores on experimental plants in the field, but not tested with rigorous trials.

\section{Hypothesis 2:effects of soil biota}

The higher growth of inoculated plants suggests an influence of mutualists, and indicates that the net effect of the soil community (pathogens + mutualists) on growing plants was generally positive. This positive effect tended to be stronger for roots inoculated with soil from the 
Solidago communities vs. soil from phylogenetically and phenotypically distinct grass communities, suggesting that mutualists may have been less prevalent in grass-dominated sites, but the marginal $\mathrm{p}$-value $(\mathrm{p}=0.088)$ suggests that this trend was weak. Solidago spp. are AMmycorrhizal, but different fungal partners can have considerably different effects on members of this genus (Klironomos 2003); appropriate AMF may have been more abundant where native Solidago were present. However, it is possible that this benefit might decline over time as pathogens accumulate in the rooting zone (e.g., MacKay \& Kotanen 2008).

\section{Implications for invasions}

Some studies have provided evidence that biotic resistance may be greater for species with close relatives in the regional flora (Strauss et al. 2006; Diez et al. 2008; Dawson et al. 2009; Hill and Kotanen 2009). Here, we have addressed a related question at a much smaller spatial scale, with different results. For a single novel invader, $S$. virgaurea, we have provided evidence suggesting that communities with abundant native congeners do not represent a greater barrier than communities dominated by phylogenetically distant species (i.e. grasses). In part, this seems to be a result of the behaviour of generalist herbivores; other recent work has suggested that invaders can be regulated more strongly by generalist than specialist enemies (Parker and Hay 2005). As well, the need for appropriate mutualists (Richardson 2000) may even result in a slight benefit to S. virgaurea in congeneric-dominated communities. Since grasses and native Solidago spp. differ greatly in many ways, including morphology, chemistry, etc., the lack of a negative response of $S$. virgaurea to native congeners in the surrounding community seems likely to be a conservative result: congeners did not have a strikingly different effect than non-congeners, even when these species were separated by large phenotypic differences. For ethical reasons, we could 
not follow S. virgaurea through the stages of naturalization and spread; however, these results suggest that at the critical initial stages of a new invasion, this species would not be inhibited by the presence of relatives.

\section{Acknowledgements}

This research was supported by Natural Sciences and Engineering Research Council of Canada (NSERC) Research and Equipment Grants (PMK), an NSERC Postgraduate Scholarship (SBH), and the Koffler Scientific Reserve at Jokers Hill. Thanks to K. Kostyukova for her continuous help, and to N. Taraban-Lagois, G. Tang, J. McKay, and A. MacDonald for their support, discussions, and field assistance. This is a publication of the Koffler Scientific Reserve. 


\section{References}

Agrios G.N. 1997. Plant Pathology, 4th edn. Academic Press, San Diego

Belanger J., and Bergeron J.M. 1987. Can alkaloids and tannins in plants influence food choice of meadow voles (Microtus pennsylvanicus). Can J Zool 65:375-378

Brandle M., and Brandl R. 2006. Is the composition of phytophagous insects and parasitic fungi among trees predictable? Oikos 113:296-304

Brandle M., Kuhn I., Klotz S., Belle C., and Brandl R. 2008. Species richness of herbivores on exotic host plants increases with time since introduction of the host. Divers Distrib 14:905-912

Cahill J.F., Kembel S.W., Lamb E.G., and Keddy P.A. 2008. Does phylogenetic relatedness influence the strength of competition among vascular plants? Perspect Plant Ecol Evol Syst 10:41-50

Cappuccino N., and Carpenter D. 2005. Invasive exotic plants suffer less herbivory than noninvasive exotic plants. Biol Lett 1:435-438

Carson W.P., and Root R.B. 1999. Top-down effects of insect herbivores during early succession: influence on biomass and plant dominance. Oecologia 121:260-272

Connell J.H. 1971. On the role of natural enemies in preventing competitive exclusion in some marine animals and in rain forest trees. In: Den Boer PJ, Gradwell G (eds) Dynamics of populations: Proceedings of the advanced study institute on dynamics of numbers of populations, Center for Agricultural Publishing and Documentation, Wageningen, pp. 298-312 
Crall A.W., Meyerson L.A., Stohlgren T.J., Jarnevich C.S., Newman G.J., and Graham J. 2006. Show me the numbers: what data currently exist for non-native species in the USA? Front Ecol Env 4:414-418

Crawley M.J. 2007. The R book. John Wiley, New York

Davis M.A., Grime J.P., and Thompson K. 2000. Fluctuating resources in plant communities: a general theory of invasibility. J Ecol 88:528-534

Dawson W., Burslem D., and Hulme P.E. 2009. Herbivory is related to taxonomic isolation, but not to invasiveness of tropical alien plants. Divers Distrib 15:141-147

Diez J.M., Sullivan J.J., Hulme P.E., Edwards G., and Duncan R.P. 2008. Darwin's naturalization conundrum: dissecting taxonomic patterns of species invasions. Ecol Lett 11:674-681

Elton C.S. 1958. The ecology of invasions by animals and plants. Methuen, London

Gilbert G.S., and Webb C.O. 2007. Phylogenetic signal in plant pathogen-host range. Proc Nat Acad Sci USA 104:4979-4983

Hawkes C.V. 2007. Are invaders moving targets? The generality and persistence of advantages in size, reproduction, and enemy release in invasive plant species with time since introduction. Am Nat 170:832-843

Hill S.B., and Kotanen P.M. 2009. Evidence that phylogenetically novel non-indigenous plants experience less herbivory. Oecologia 161:581-590

Hill S.B., and Kotanen P.M. 2010. Phylogenetically structured damage on Asteraceae: susceptibility of native and exotic species to foliar herbivores. Biol Inv 12: 3333-3342.

Hill S.B., and Kotanen P.M. 2011. Phylogenetic structure predicts capitular damage to Asteraceae better than origin or phylogenetic distance to natives. Oecologia 166: 843851. 
Jakobs G., Weber E., and Edwards P.J. 2004. Introduced plants of the invasive Solidago gigantea (Asteraceae) are larger and grow denser than conspecifics in the native range. Divers Distrib 10:11-19

Janzen D.H. 1970. Herbivores and the number of tree species in tropical forests. Am Nat 104:501-528

Jobin A., Schaffner U., and Nentwig W. 1996. The structure of the phytophagous insect fauna on the introduced weed Solidago altissima in Switzerland. Entomologia Experimentalis Et Applicata 79:33-42

Kauffman M.J., and Maron J.L. 2006. Consumers limit the abundance and dynamics of a perennial shrub with a seed bank. Am Nat 168:454-470

Keane R.M., and Crawley M.J. 2002. Exotic plant invasions and the enemy release hypothesis. Trends Ecol Evol 17:164-170

Kirk R.E. 1995. Experimental design: procedures for the behavioral sciences, 3rd edn. Brooks/Cole, Pacific Grove

Klironomos J.N. 2002. Feedback with soil biota contributes to plant rarity and invasiveness in communities. Nature 417:67-70

Klironomos J.N. 2003. Variation in plant response to native and exotic arbuscular mycorrhizal fungi. Ecology 84:2292-2301

Levine J.M., Adler P.B., and Yelenik S.G. 2004. A meta-analysis of biotic resistance to exotic plant invasions. Ecol Lett 7:975-989

Liu H., and Stiling P. 2006. Testing the enemy release hypothesis: a review and meta-analysis. Biol Inv 8: 1535-1545 
Mack R.N. 1996. Predicting the identity and fate of plant invaders: Emergent and emerging approaches. Biol Cons 78:107-121

Mack R.N., Simberloff D., Lonsdale W.M., Evans H., Clout M., and Bazzaz F.A. 2000. Biotic invasions: causes, epidemiology, global consequences, and control. Ecol Appl 10:689710

MacKay J., and Kotanen P.M. 2008. Local escape of an invasive plant, common ragweed (Ambrosia artemisiifolia L.), from above-ground and below-ground enemies in its native area. J Ecol 96: 1152-1161

Maddox G.D., and Root R.B. 1987. Resistance to 16 diverse species of herbivorous insects within a population of goldenrod, Solidago altissima - genetic variation and heritability. Oecologia 72:8-14

Manson R.H., Ostfeld R.S., and Canham C.D. 2001. Long-term effects of rodent herbivores on tree invasion dynamics along forest-field edges. Ecology 82:3320-3329

Mitchell C.E., Agrawal A.A., Bever J.D., Gilbert G.S., Hufbauer R.A., Klironomos J.N., Maron J.L., Morris W.F., Parker I.M., Power A.G., Seabloom E.W., Torchin M.E., and Vazquez D.P. 2006/ Biotic interactions and plant invasions. Ecol Lett 9:726-740

Mitchell C.E., and Power A.G. 2003. Release of invasive plants from fungal and viral pathogens. Nature 421:625-627

Moenting A.E., and Morris D.W. 2006. Disturbance and habitat use: is edge more important than area? Oikos 115:23-32

Odegaard F., Diserud O.H., and Ostbye K. 2005. The importance of plant relatedness for host utilization among phytophagous insects. Ecol Lett 8:612-617 
Parker J.D., and Hay M.E. 2005. Biotic resistance to plant invasions? Native herbivores prefer non-native plants. Ecol Lett 8:959-967

Pimentel D., Lach L., Zuniga R., and Morrison D. 2000. Environmental and economic costs of nonindigenous species in the United States. Bioscience 50:53-65

Rejmánek, M. 1996. A theory of seed plant invasiveness: the first sketch. Biol Conserv 78:171181

Richardson D.M., Allsopp N., D'Antonio C., Milton S.J., and Rejmánek M. 2000. Plant invasions - the role of mutualisms. Biol Rev 75:65-93

Stireman J.O., Nason J.D., and Heard S.B. 2005. Host-associated genetic differentiation in phytophagous insects: general phenomenon or isolated exceptions? Evidence from a goldenrod-insect community. Evolution 59:2573-2587

Strauss S.Y., and Agrawal A.A. 1999. The ecology and evolution of plant tolerance to herbivory. Trends Ecol Evol 14:179-185

Strauss S.Y., Webb C.O., and Salamin N. 2006. Exotic taxa less related to native species are more invasive. Proc Nat Acad Sci USA 103:5841-5845

Torchin M.E., Lafferty K.D., Dobson AP, McKenzie V.J., and Kuris A.M. 2003. Introduced species and their missing parasites. Nature 421:628-630

Webb C.O., Ackerly D.D., McPeek M.A., and Donoghue M.J. 2002. Phylogenies and community ecology. Annu Rev Ecol Syst 33:475-505

Weiblen G.D., Webb C.O., Novotny V., Basset Y., and Miller S.E. 2006. Phylogenetic dispersion of host use in a tropical insect herbivore community. Ecology 87:S62-S75

Williamson M. 1996. Biological Invasions. Chapman and Hall, London 
Table 1. Analyses of variance for foliar damage and survival of Solidago virgaurea.

"Community" includes grass, Solidago canadensis, and mixed Solidago canadensis and S. nemoralis communities; "Vegetation" includes surrounding plants being left intact or removed; " $\mathrm{C} \times \mathrm{V}$ " is the interaction between community type and vegetation removal. Damage and survival measures were Z-score transformed before analysis.

\begin{tabular}{lccccc}
\hline \hline & & \multicolumn{2}{c}{ Damage } & \multicolumn{2}{c}{ Survival } \\
\hline Source & df & $\mathrm{F}^{1}$ & $\mathrm{p}$ & $\mathrm{F}$ & $\mathrm{p}$ \\
Community & 2 & 2.212 & 0.152 & 2.621 & 0.114 \\
Vegetation & 1 & 54.671 & 0.007 & 29.465 & $<0.001$ \\
$\mathrm{C} \times \mathrm{V}$ & 2 & 9.602 & 0.003 & 3.715 & 0.056 \\
\hline \hline
\end{tabular}

${ }^{1}$ For all F-ratios denominator $\mathrm{df}=12$ 
Table 2. Analysis of variance of shoot and root growth for Solidago virgaurea grown in soils inoculated with sterilized vs. intact soil biota from different community types (grass, Solidago canadensis, and mixed Solidago canadensis and S. nemoralis); "C×S" is the interaction between community type and sterilization treatment.

\begin{tabular}{lccccc}
\hline \hline & & \multicolumn{2}{c}{ Shoot Mass } & \multicolumn{2}{c}{ Root Mass } \\
\hline Source & $\mathrm{df}$ & $\mathrm{F}^{1}$ & $\mathrm{p}$ & $\mathrm{F}$ & $\mathrm{p}$ \\
Community & 2 & 3.565 & 0.061 & 3.702 & 0.056 \\
Sterilization & 1 & 3.420 & 0.089 & 9.390 & 0.010 \\
$\mathrm{C} \times \mathrm{S}$ & 2 & 1.100 & 0.364 & 1.647 & 0.233 \\
\hline \hline
\end{tabular}

${ }^{1}$ For all F-ratios denominator $\mathrm{df}=12$ 


\section{Figure captions}

Figure 1. Effects of vegetation removal on foliar damage in communities dominated by grass, Solidago canadensis, and mixed Solidago canadensis and S. nemoralis. Symbols represent the mean proportion of leaf area damaged per plant $( \pm$ SE) for each treatment combination.

Figure 2. Survival of Solidago virgaurea in communities dominated by grass, Solidago canadensis, and mixed Solidago canadensis and S. nemoralis when adjacent vegetation was left intact or was removed. Symbols represent the mean proportion surviving ( $\pm \mathrm{SE}$ ).

Figure 3. Shoot (a) and root (b) biomass of Solidago virgaurea when exposed to sterilized or non-sterilized soils from communities dominated by grass, Solidago canadensis, and mixed Solidago canadensis and S. nemoralis. Symbols represent mean ( \pm SE) for each community x treatment combination. 


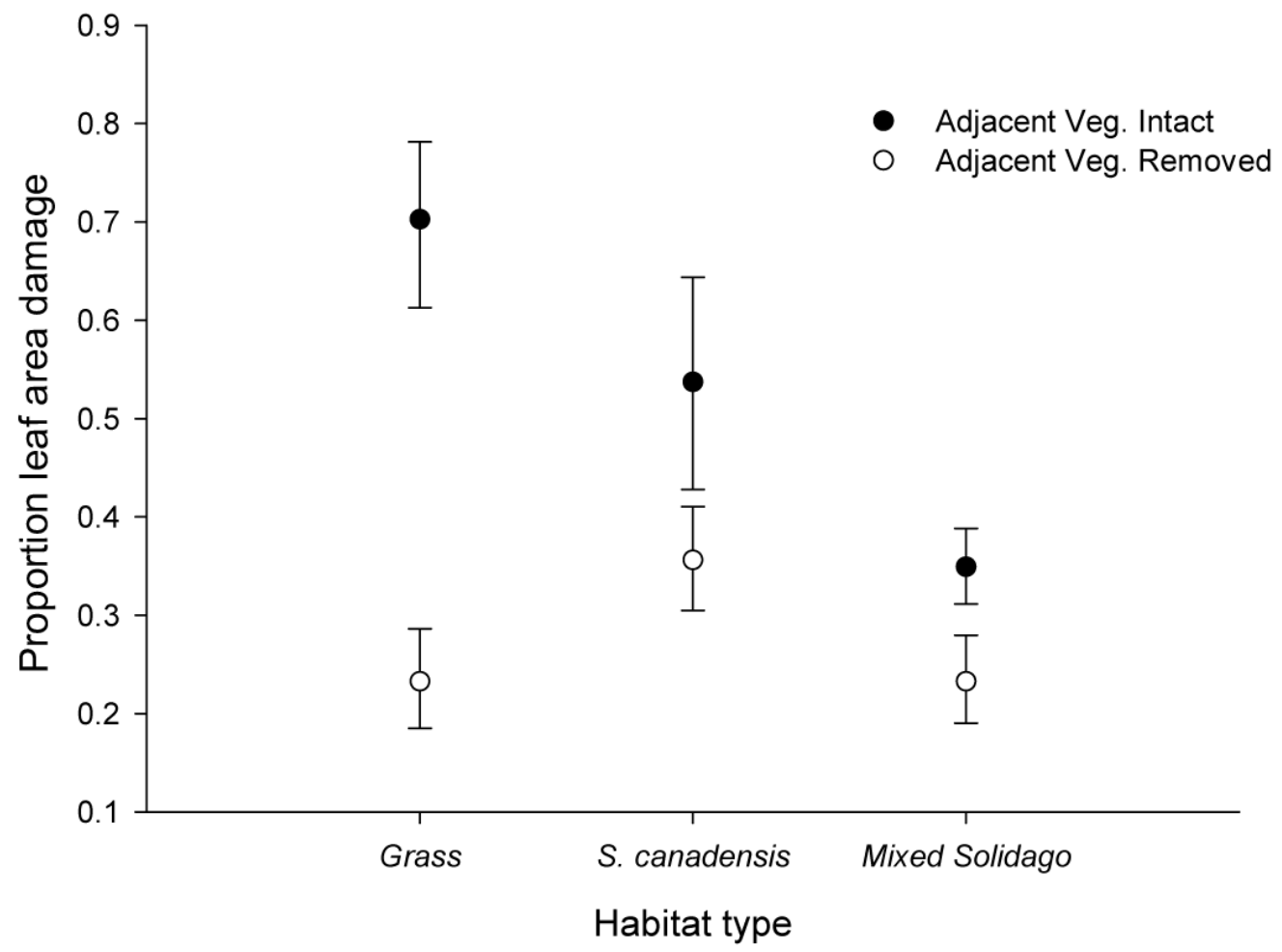




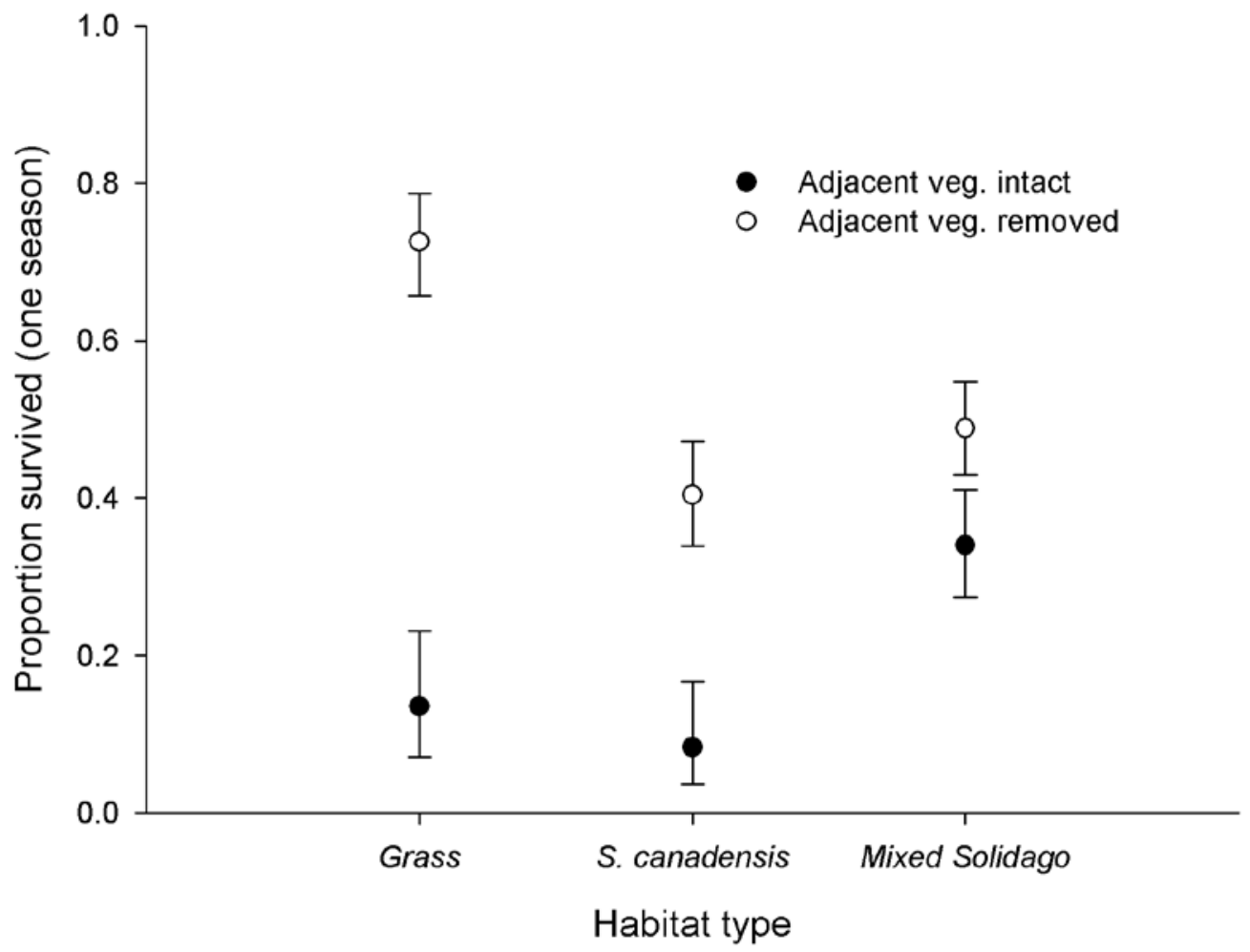



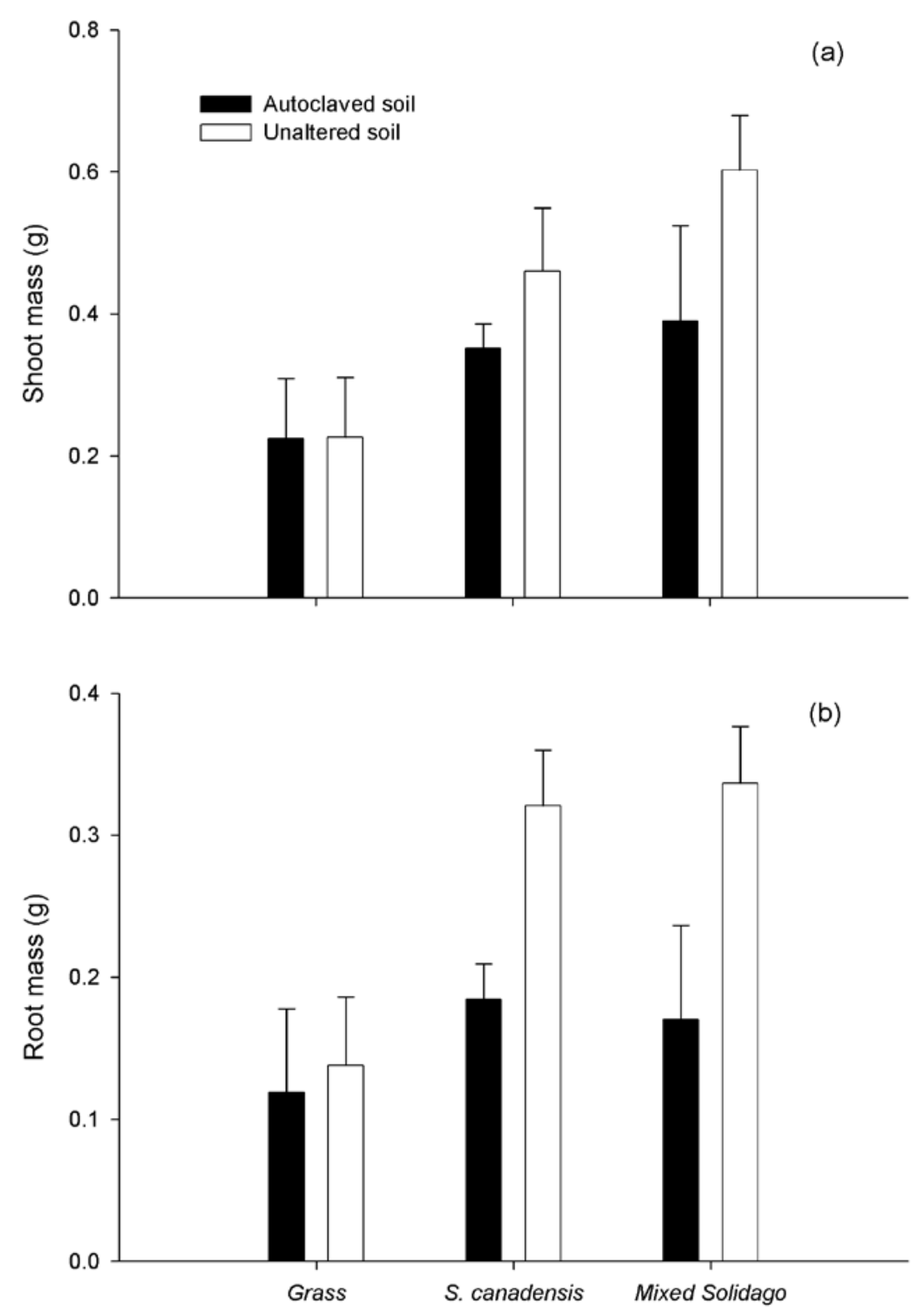

Habitat type 